\title{
The effect of different non-linear demand response models considering incentive and penalty on transmission expansion planning
}

\author{
Amir Sadegh Zakeri, Oveis Asgari Gashteroodkhani, Iman Niazazari, Hossein Askarian-Abyaneh
}

\begin{abstract}
The Transmission Expansion Planning (TEP) problem involves adding new lines to the existing electrical transmission network in order to meet the electrical demand requirements. Demand Response (DR) plays an important role in solving the TEP problem due to the delay in the investment costs. Researchers usually focus on the linear model of DR, while the focus on nonlinear models including power, exponential and logarithmic of DR is small. In this paper and in order to understand which model gives the realistic results, the linear model of $D R$ is studied simultaneously with nonlinear models including power, exponential and logarithmic of DR. Moreover, the effect of incentive and penalty which has been neglected in the studies, is investigated. The study is investigated based on the viewpoint of different participants of the market including Independent System Operator (ISO), Customers and Utilities. In order to prioritize and select the most effective DR program, five characteristics including Peak Reduction, Energy Consumption, Load Factor, Peak to Valley and Customer's Total Cost are extracted from the load curve. Then, using the weighting coefficients obtained by Entropy technique and implementing the TOPSIS and AHP technique, different DR programs are prioritized.
\end{abstract}

Index Terms - AHP, Customers, Demand Response, Entropy technique, Independent System Operator, Transmission Expansion Planning, TOPSIS, Utilities

\section{INTRODUCTION}

The Transmission Expansion Planning (TEP) problem involves adding new lines to the existing electrical transmission network in order to meet the electrical demand requirements, taking into account technical and financial constraints during the predefined planning horizon [1].

TEP is a large-scale mixed-integer nonlinear optimization problem which includes many equality and inequality constraints. The techniques used to solve these types of problems can be categorized into three different techniques including evolutionary techniques [2-9], mathematical techniques [10-12] and meta-heuristic techniques [13-17].

The first example for evolutionary technique in solving TEP problems was presented in [4] where TEP was formulated as a load distribution problem and the objective

Amir Sadegh Zakeri and Hossein Askarian-Abyaneh are with Department of Electrical Engineering, Amirkabir University of Technology, Tehran, Iran.

Oveis Asgari Gashteroodkhani and Iman Niazazari are with Department of Electrical and Biomedical Engineering, University of Nevada, Reno, USA (e-mail: oveisa@nevada.unr.edu). function and the constraints was modelled by linear functions. The effect of ohmic power losses was ignored and linear load flow was calculated by considering the newly added lines until no overload was found in the system. The other example is [5] where TEP problem was divided into two stages which in the first stage, investment was solved by an evolutionary technique, and in the second stage, generation was solved by a known optimization technique. Sensitivity analysis was used in another studies of evolutionary technique [6-8] to solve TEP problem. In these studies, it is used sensitivity index to determine the added lines. Different algorithms such as load feeding [6], lowest criteria [7] and the optimal load flow [8] was used to make sensitivity index.

Linear programming is the most well-known mathematical technique for solving TEP problem [10]. The TEP problem was divided into two stages including investment and generation where linear planning model and Monte Carlo was used to solve the stages based on DC load flow. The nonlinear planning is another mathematical technique for solving TEP problem where the objective function and some constraints was formulated by nonlinear equations. In this technique, the output result may get stuck in the local solution and this is the main disadvantage of this technique. Mathematical decomposition was used in [12] where was another example for mathematical technique for solving TEP problem.

Meta-heuristic techniques were proposed to use the advantage of the evolutionary and mathematical techniques. An Imperialistic Competitive Algorithm (ICA) is a metaheuristic algorithm that shows excellent results in different applications. In [13], ICA is used and its superior compared to several other heuristic methods is verified. A parallel SA algorithm which significantly reduced the computation burden and improved quality of the SA solution was proposed in [14]. A greedy randomization adaptive search procedure was investigated in [15]. Particle swarm optimization (PSO) is another heuristic method that has gained lots of attention due to its effectiveness. In [16], this method is used to provide better accuracy by tuning the parameters of a machine learning model. In [18] a novel multiobjective approach to the Stochastic Fractal Search algorithm namely Non-Dominated Ranking SFS (NR-SFS) is introduced and applied to find the optimum solution to the nonlinear constrained problem. The outcome of reference [18] shows the effectiveness of the proposed method in providing secure operation of a microgrid in presence of uncertainties.

Because of the delay in the investment costs, Demand Response (DR) plays an important role in solving the TEP problem [19-21]. DR is essentially a change in the energy 
usage pattern of the end-use customers from its intended power in response to the power changes or incentives [23]. Customers will benefit due to incentives and Independent System Operator (ISO) will benefit due to load reduction in its electrical network. The usefulness of DR has been proved in the United States [24], and other countries [25]. In investment and DR, Data Envelopment Analysis (DEA) plays an important role as well. DEA is a nonparametric method in operations research economics for the estimation of production frontiers. DEA can be addressed through diverse computational, and combinatorial models [26, 27].

In the studies, linear model of DR is usually used, while the focus on nonlinear models including power, exponential and logarithmic of DR is small. It is illustrated that the nonlinear model with power structure of DR gives better results [28]. Also, in [29] the nonlinear model with logarithmic structure of DR is used. In order to understand which model gives the realistic results, the linear model of DR should be studied simultaneously with nonlinear models including power, exponential and logarithmic of DR. In the definition of DR, incentive and penalty is used as one of the main reasons for changing the energy usage pattern of the end-use customers from its intended power which has been neglected in the studies. There are different participants in the market which their viewpoint should be considered. Independent System Operator (ISO), Customers and Utilities are members of the market where has different opinions. In order to prioritize and select the most effective DR program, five characteristics including Peak Reduction, Energy Consumption, Load Factor, Peak to Valley and Customer's Total Cost are extracted from the load curve. Then, using the weighting coefficients obtained by Entropy technique and implementing the TOPSIS and AHP technique, different DR programs are prioritized. On this basis, our contribution in this paper is as follow:

- Find the effect of linear and nonlinear models of DR.

- Find the effect of incentive and penalty.

- Considering the viewpoint of different participants of the market in prioritize DR programs.

On this basis and in the following, the formulation of linear and nonlinear models of DR considering incentive and penalty are presented in 2 . In section 3 and 4 , incentive and penalty formulation and procedure of DR program prioritization are provided, respectively. Simulation and results are provided in section 5 and finally in section 6 , the conclusion are provided.

\section{DIFFERENT MODELS OF DR}

Elasticity can be defined as the sensitivity of demand to price [28]:

$$
E(i, j)=\frac{\partial d(i)}{\partial \rho(j)} \cdot \frac{\rho_{0}(j)}{d_{0}(i)} \quad j=1,2, \ldots, 24
$$

where $\mathrm{d}(\mathrm{i})$ is the customer demand in $\mathrm{i}$-th hour, d0(i) is the initial customer demand in $i$-th hour, $\rho(i)$ is the spot electricity price in i-th hour, $\rho 0(\mathrm{i})$ is the initial electricity price in $\mathrm{i}$-th hour. If $\mathrm{B}(\mathrm{i})$ is assumed as the benefit of customer during $\mathrm{i}$-th hour, then, the customer benefit (S) can be obtained as follow:
$S=B(\mathrm{i})-\mathrm{d}(\mathrm{i}) \cdot \rho(\mathrm{i})$

The difference in customer demand with respect to his/her initial demand during i-th hour can be stated as:

$\Delta d(\mathrm{i})=d(\mathrm{i})-\mathrm{d}_{0}(\mathrm{i})$

If the customer are paid A(i) for each $\mathrm{kWh}$ load reduction during i-th hour, the total incentive during i-th hour can be written as:

$$
P(\Delta d(\mathrm{i}))=A(\mathrm{i})\left(\mathrm{d}_{0}(\mathrm{i})-d(\mathrm{i})\right)
$$

The penalty will be applied for a customer who does not comply with his/her own contract requirements. If the contract level and penalty are stated by IC(i) and Pen(i) during i-th hour, the total penalty during $i$-th hour can be shown as:

$$
\operatorname{PEN}(\Delta d(\mathrm{i}))=\operatorname{Pen}(\mathrm{i})\left[\mathrm{IC}(\mathrm{i})-\left\{\mathrm{d}_{0}(\mathrm{i})-d(\mathrm{i})\right\}\right]
$$

By considering the incentive and penalty, the equation (2) can be rewritten as follow:

$$
S=B(\mathrm{~d}(i))-d(i) \cdot \rho(i)+\mathrm{P}(\Delta \mathrm{d}(\mathrm{i}))-\mathrm{PEN}(\Delta \mathrm{d}(\mathrm{i}))
$$

Based on the classical optimization rules, and to obtain the maximum customer profit, the differentiation of $\mathrm{S}$ shall be equal zero.

$$
\begin{aligned}
& \frac{\partial S}{\partial d(i)}=\frac{\partial B(\mathrm{~d}(i))}{\partial d(i)}-\rho(i)+\frac{\partial P}{\partial d(i)}-\frac{\partial P E N}{\partial d(i)}=0 \\
& \frac{\partial B(\mathrm{~d}(i))}{\partial d(i)}=\rho(i)+A(\mathrm{i})+\operatorname{Pen}(\mathrm{i})
\end{aligned}
$$

Linear and nonlinear models including power, exponential and logarithmic are prevalent for the customer's response. In the following, Taylor expansion of $\mathrm{B}(\mathrm{i})$ has been shown for these different structures:

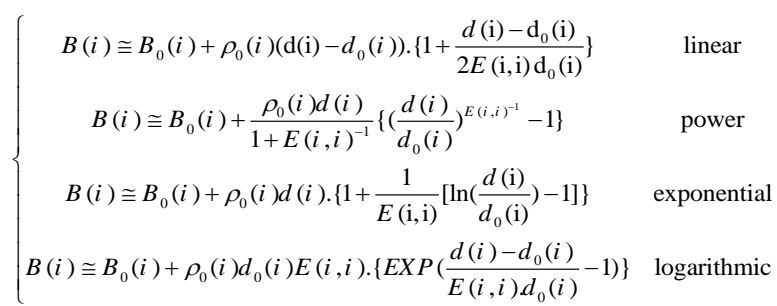

The differentiation of B(i) can be obtained as follow:

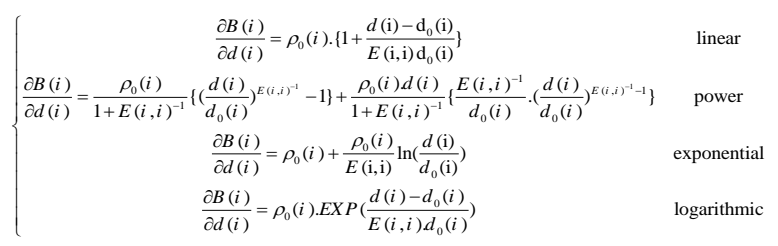

By Substituting (8) and (10), the following equation is obtained:

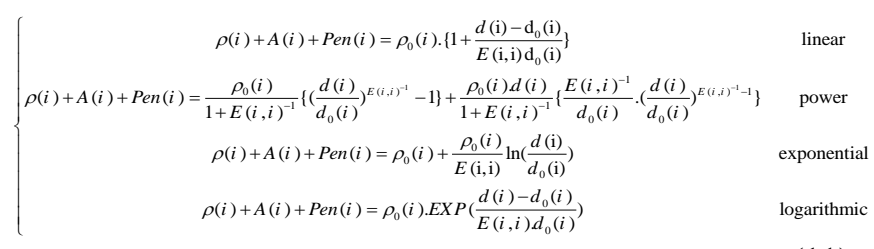



follows:

The solution of the above equations is obtained as $\left\{\begin{array}{cc}d(i)=d_{0}(i)\left\{1+E(i, i) \cdot \frac{\rho(i)-\rho_{0}(i)+A(i)+\operatorname{Pen}(i)}{\rho_{0}(i)}\right\} & \text { linear } \\ \left.d(\mathrm{i})=d_{0}(\mathrm{i}) \cdot\left(\frac{\left(\mathrm{A}(\mathrm{i})+\operatorname{Pen}(\mathrm{i})+\rho(\mathrm{i})+\rho_{0}(\mathrm{i})\right) \cdot E(\mathrm{i}, \mathrm{i})+\mathrm{A}(\mathrm{i})+\operatorname{Pen}(\mathrm{i})+\rho(\mathrm{i})}{\rho_{0}(\mathrm{i}) \cdot(\mathrm{E}(\mathrm{i}, \mathrm{i})+1)}\right)^{E(\mathrm{i})}\right) & \text { power } \\ d(i)=d_{0}(\mathrm{i}) \cdot \exp \left(\frac{E(\mathrm{i}, \mathrm{i})\left(A(i)+\operatorname{Pen}(i)+\rho(i)-\rho_{0}(i)\right)}{\rho_{0}(i)}\right) & \text { exponential } \\ d(i)=d_{0}(i)\left\{1+E(i, i) \cdot \ln \left(\frac{\rho(i)+A(i)+\operatorname{Pen}(i)}{\rho_{0}(i)}\right)\right\} & \text { logarithmic }\end{array}\right.$ (12)

The above equations represent single period model, while in the following, multi period model are presented:

$$
\left\{\begin{array}{cc}
d(i)=d_{0}(i)\left\{1+\sum_{j=1}^{24} E(i, j) \cdot \frac{\rho(j)-\rho_{0}(j)+A(j)+\operatorname{Pen}(j)}{\rho_{0}(j)}\right\} & \text { linear } \\
d(\mathrm{i})=d_{0}(\mathrm{i}) \cdot \prod_{j=1}^{24}\left(\frac{\left(\mathrm{A}(j)+\operatorname{Pen}(j)+\rho(j)+\rho_{0}(j)\right) \cdot E(\mathrm{i}, j)+\mathrm{A}(j)+\operatorname{Pen}(j)+\rho(j)}{\rho_{0}(j) \cdot(\mathrm{E}(\mathrm{i}, j)+1)}\right)^{E(\mathrm{i}, j)} & \text { power } \\
d(i)=d_{0}(\mathrm{i}) \cdot \exp \left(\sum_{j=1}^{24} \frac{E(\mathrm{i}, j)\left(A(j)+\operatorname{Pen}(j)+\rho(j)-\rho_{0}(j)\right)}{\rho_{0}(j)}\right) & \text { exponential } \\
d(i)=d_{0}(i)\left\{1+\sum_{j=1}^{24} E(i, j) \cdot \ln \left(\frac{\rho(j)+A(j)+\operatorname{Pen}(j)}{\rho_{0}(j)}\right)\right\} & \text { logarithmic }
\end{array}\right.
$$

\section{INCEPTIVE AND PENALTY FORMULATION}

For linear incentive and penalty, the values are considered 100 and $50 \$ / \mathrm{kW} . \mathrm{h}$, respectively. For nonlinear incentive and penalty, it is used the following equations:

$$
A(\mathrm{t})=\frac{d_{0}(\mathrm{t})}{d_{\text {min(peakinterval) }}} A
$$

$$
P(\mathrm{t})=\frac{d_{0}(\mathrm{t})}{d_{\text {min(peakinterval) }}} P e n
$$

where $\mathrm{A}$ is linear incentive equal to $100 \$ / \mathrm{kW} . \mathrm{h}$, Pen is linear penalty equal to $50 \$ / \mathrm{kW} . \mathrm{h}, \mathrm{d}_{0}(\mathrm{t})$ is demand at time t, $\mathrm{d}_{\text {min(peak interval) }}$ is the minimum demand in the peak period, $\mathrm{A}(\mathrm{t})$ is nonlinear incentive and $\mathrm{P}(\mathrm{t})$ is nonlinear penalty.

\section{PROCEDURE OF DR PROGRAM PRIORITIZATION}

The main goal of this section is to prioritize and select the most effective DR program where the load characteristics approaches the desired one. For this purpose, five characteristics including Peak Reduction, Energy Consumption, Load Factor, Peak to Valley and Customer's Total Cost are extracted from the load curve. Then, using the Entropy technique [30], weighting coefficients are given to the above characteristics. Since each market participant have its own viewpoint, there are different weighing coefficients for each one. The weighting coefficients for different market participants (ISO, Utility and Customer) versus load features are provided in Table I. Based on the weighting coefficients and implementing the TOPSIS [31], the prioritization of the different DR programs is obtained.

TABLE I: THE WEIGHTING COEFFICIENTS FOR DIFFERENT MARKET PARTICIPANTS (ISO, UTILITY AND CUSTOMER) VERSUS LOAD FEATURES

\begin{tabular}{cccccc}
\hline \hline Feature & $\begin{array}{c}\text { Peak } \\
\text { Reduction }\end{array}$ & $\begin{array}{c}\text { Energy } \\
\text { Consumption }\end{array}$ & $\begin{array}{c}\text { Load } \\
\text { Factor }\end{array}$ & $\begin{array}{c}\text { Peak } \\
\text { to } \\
\text { Valley }\end{array}$ & $\begin{array}{c}\text { Customer's } \\
\text { Total Cost }\end{array}$ \\
\hline \hline ISO & 0.3 & 0.1 & 0.3 & 0.2 & 0.1 \\
\hline Utility & 0.1 & 0.1 & 0.2 & 0.1 & 0.5 \\
\hline Customer & 0.1 & 0.2 & 0.1 & 0.1 & 0.5 \\
\hline
\end{tabular}

In the following, the market regulator should determine each market participant's weight. Table II shows a pair comparison of market participants based on expert's viewpoints. The AHP technique [32] is used to obtain decision maker weights where has been shown in the final column of Table III [33]. As can be seen, the opinion of the ISO is in the first rank with $57 \%$ and opinion of the customer and utility is in the second and third rank with 29 $\%$ and $14 \%$. Finally, the priority of DR programs are obtained by market regulator.

TABLE II: PAIR COMPARISONS BY AHP TECHNIQUE [33]

\begin{tabular}{ccccc}
\hline \hline Feature & ISO & Utility & Customer & Weight \\
\hline \hline ISO & 1 & 4 & 2 & 0.57 \\
\hline Utility & 0.25 & 1 & 0.5 & 0.14 \\
\hline Customer & 0.5 & 2 & 1 & 0.29 \\
\hline
\end{tabular}

\section{Simulation Results}

To find the effect of linear and nonlinear models of DR and the effect of incentive and penalty, the DR is applied on a typical load considering the following scenarios:

1. Linear Demand Response (LDR);

2. Nonlinear Demand Response (NLDR) based on Power modelling;

3. NLDR based on Exponential modelling;

4. NLDR based on Logarithmic modelling;

5. DR considering linear incentive and penalty;

6. NLDR based on Power modelling considering linear incentive and penalty;

7. NLDR based on Exponential modelling considering linear incentive and penalty;

8. NLDR based on Logarithmic modelling considering linear incentive and penalty;

9. LDR considering nonlinear incentive and penalty;

10. NLDR based on Power modelling considering nonlinear incentive and penalty;

11. NLDR based on Exponential modelling considering nonlinear incentive and penalty;

12. NLDR based on Logarithmic modelling considering nonlinear incentive and penalty;

In Table III, self- and cross-elasticity of load have been provided.

TABLE III: SELF- AND CROSS-ELASTICITY OF LOAD

\begin{tabular}{cccc}
\hline \hline & Valley & Off-Peak & Peak \\
\hline \hline Valley & -0.10 & 0.01 & 0.012 \\
\hline Off-Peak & 0.01 & -0.10 & 0.016 \\
\hline Peak & 0.012 & 0.016 & -0.10 \\
\hline
\end{tabular}

In Fig. 1, the effect of different load modelling on DR (scenarios 1-4) has been shown. As can be seen, the load has been significantly decreased in peak period for all linear, power, logarithmic and exponential model types. This decrease is more in linear model among other models. In off-peak period, the load has slightly increased and in valley period, the load has increased as it is desired for researchers.

In Fig. 2 the effect of different load modelling on DR considering linear incentive and penalty (scenarios 5-8) has been shown. Similar to the previous, load has significantly 
decreased in all four models in the peak period and the largest decrease is related to the linear model. In off-peak period, the load has slightly increased. In valley period, the results of the linear, logarithmic and exponential models are almost similar to each other, but the results of the power model have a large difference with the rest of the methods. By comparing Fig. 1 and Fig. 2, the effect of incentive and penalty can be found. The most significant issue is that in the linear model with the presence of incentive and penalty, the amount of reduction is much higher than the linear model without incentive and penalty, which shows that the use of appropriate DR model is essential.

In Fig. 3 the effect of different load modelling on DR considering nonlinear incentive and penalty (scenarios 9-12) has been shown. Similar to the results obtained in Fig. 2, the above results are obtained.

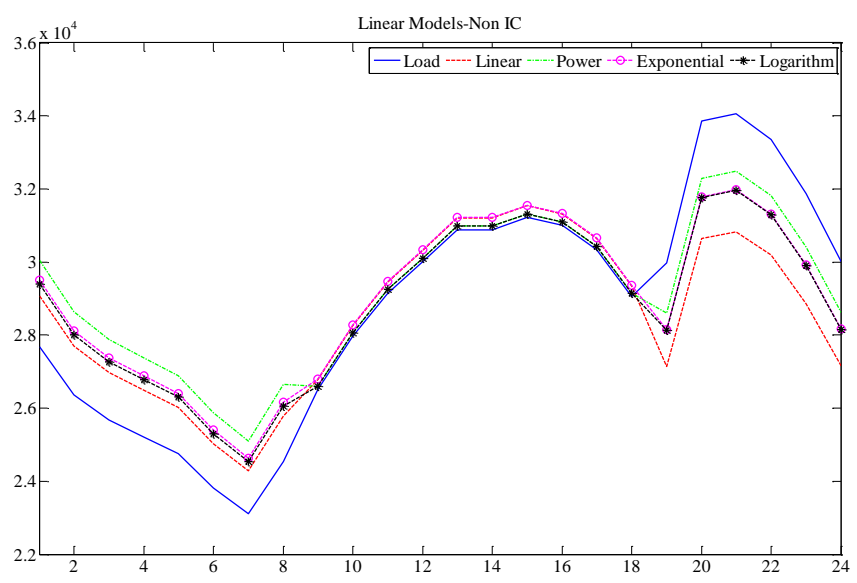

Fig. 1. The effect of different load modelling on DR (scenarios 1-4)

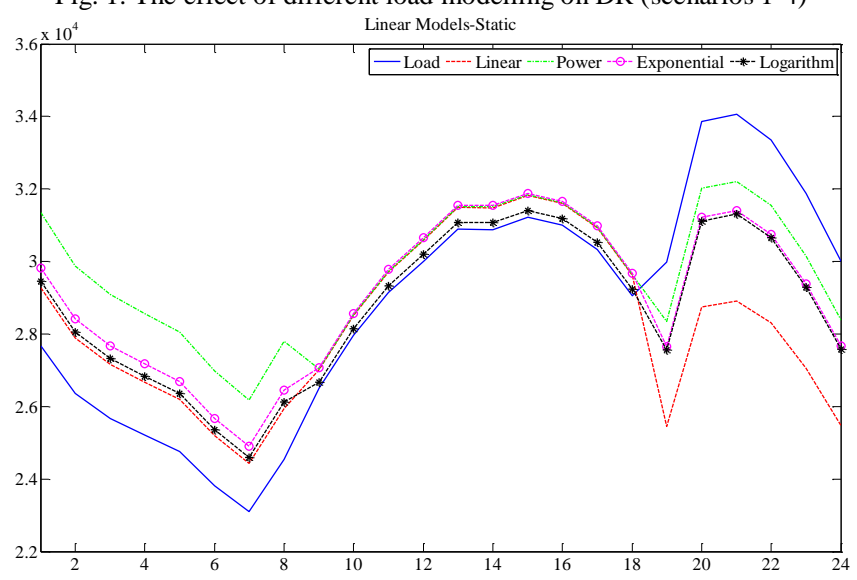

Fig. 2: The effect of different load modelling on DR considering linear incentive and penalty (scenarios 5-8)

Based on the section 4, prioritization of scenarios are obtained which can be seen in Table IV. Based on the above results, the NLDR based on Logarithmic modelling considering linear incentive and penalty leads to the best solution. In fact, this method is a realistic solution which is far from bad solutions is close to best solutions. Based on the above results, the NLDR based on Logarithmic modelling considering linear incentive and penalty leads to the best solution. In fact, this method is a realistic solution which is far from bad solutions is close to best solutions.

Based on the above results, the NLDR based on Logarithmic modelling considering linear incentive and penalty leads to the best solution. In fact, this method is a realistic solution which is far from bad solutions is close to best solutions.

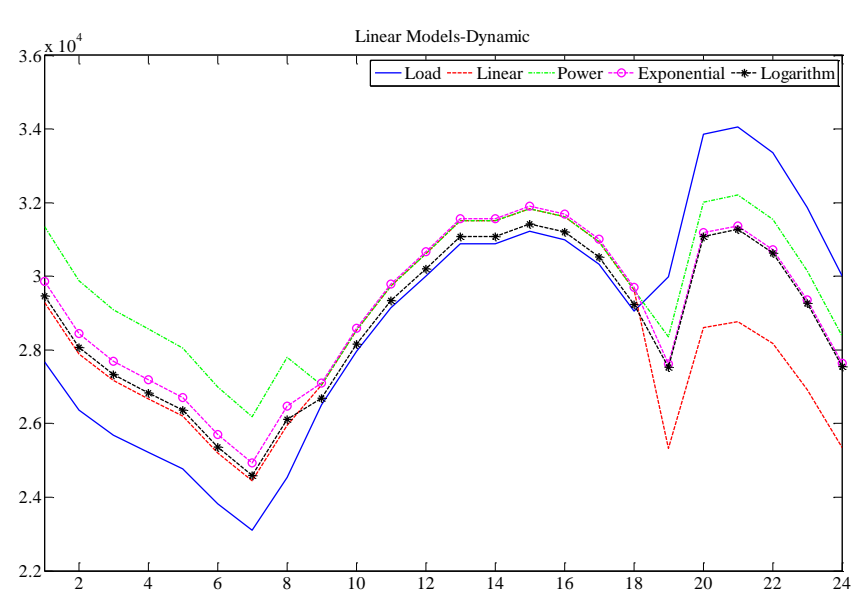

Fig. 3: The effect of different load modelling on DR considering nonlinear incentive and penalty (scenarios 9-12)

TABLE IV: PRIORITIZATION OF SCENARIOS BASED ON SECTION 4

\begin{tabular}{|c|c|c|c|c|c|c|}
\hline $\begin{array}{c}\text { Priori } \\
\text { ty }\end{array}$ & $\begin{array}{l}\text { Scenar } \\
\text { io }\end{array}$ & $\begin{array}{c}\text { Peak } \\
\text { Reducti } \\
\text { on }\end{array}$ & $\begin{array}{c}\text { Energy } \\
\text { Consumpt } \\
\text { ion }\end{array}$ & $\begin{array}{l}\text { Load } \\
\text { Factor }\end{array}$ & $\begin{array}{c}\text { Peak } \\
\text { to } \\
\text { Valle } \\
y\end{array}$ & $\begin{array}{c}\text { Custome } \\
\text { r's Total } \\
\text { Cost }\end{array}$ \\
\hline 1 & 8 & 7.7723 & 690496 & $\begin{array}{c}91.59 \\
46\end{array}$ & $\begin{array}{c}6817 . \\
16\end{array}$ & $\begin{array}{c}1359587 \\
85\end{array}$ \\
\hline 2 & 12 & 7.7549 & 690352 & $\begin{array}{c}91.55 \\
82\end{array}$ & $\begin{array}{c}6819 . \\
79\end{array}$ & $\begin{array}{c}1358785 \\
37\end{array}$ \\
\hline 3 & 1 & 7.3973 & 686272 & $\begin{array}{c}90.66 \\
56\end{array}$ & $\begin{array}{c}7257 . \\
79\end{array}$ & $\begin{array}{c}1348491 \\
01\end{array}$ \\
\hline 4 & 5 & 6.5724 & 679440 & $\begin{array}{c}88.97 \\
04\end{array}$ & $\begin{array}{c}7382 . \\
74\end{array}$ & $\begin{array}{c}1310401 \\
80\end{array}$ \\
\hline 5 & 9 & 6.5117 & 678937 & $\begin{array}{c}88.84 \\
69\end{array}$ & $\begin{array}{c}7391 . \\
93\end{array}$ & $\begin{array}{c}1307599 \\
42\end{array}$ \\
\hline 6 & 7 & 6.3882 & 698233 & $\begin{array}{c}91.25 \\
15\end{array}$ & $\begin{array}{c}6977 . \\
51\end{array}$ & $\begin{array}{c}1371107 \\
47\end{array}$ \\
\hline 7 & 11 & 6.3143 & 698478 & $\begin{array}{c}91.21 \\
14 \\
\end{array}$ & $\begin{array}{c}6982 . \\
23 \\
\end{array}$ & $\begin{array}{c}1370941 \\
74\end{array}$ \\
\hline 8 & 4 & 6.1631 & 692817 & $\begin{array}{c}90.32 \\
64\end{array}$ & $\begin{array}{c}7418 . \\
18\end{array}$ & $\begin{array}{c}1372526 \\
14\end{array}$ \\
\hline 9 & 3 & 6.1248 & 696015 & $\begin{array}{c}90.70 \\
63\end{array}$ & $\begin{array}{c}7335 . \\
39\end{array}$ & $\begin{array}{c}1377152 \\
77\end{array}$ \\
\hline 10 & 6 & 5.4293 & 713493 & $\begin{array}{c}92.30 \\
02\end{array}$ & $\begin{array}{c}6029 . \\
53\end{array}$ & $\begin{array}{c}1397596 \\
86\end{array}$ \\
\hline 11 & 10 & 5.4293 & 713493 & $\begin{array}{c}92.30 \\
02\end{array}$ & $\begin{array}{c}6029 . \\
53\end{array}$ & $\begin{array}{c}1397596 \\
86\end{array}$ \\
\hline 12 & 2 & 4.6007 & 700665 & $\begin{array}{c}89.85 \\
35\end{array}$ & $\begin{array}{c}7397 . \\
25\end{array}$ & $\begin{array}{c}1388472 \\
95\end{array}$ \\
\hline
\end{tabular}

Figure 4 shows the priority of scenarios based on legislator's viewpoint which is considered main participant' viewpoint in the market. As can be seen, the NLDR based on Logarithmic modelling considering linear incentive and penalty is in the top rank and NLDR based on Logarithmic modelling considering nonlinear incentive and penalty is in the next step. On this basis, the legislator will assure that not also reliability issues have been considered but also participant's benefit are provided by running the NLDR based on Logarithmic modelling considering linear incentive and penalty.

In order to further investigate the proposed technique, the above technique is implemented on the IEEE 57-bus electrical network. To do this, DR are performed while the load of buses 9, 12, 16 and 18 are considered as office,

commercial, residual and residual, respectively. Similar to previous, three scenarios are performed including:

- Without considering incentive and penalty;

- Considering linear incentive and penalty; 
- Considering nonlinear incentive and penalty;

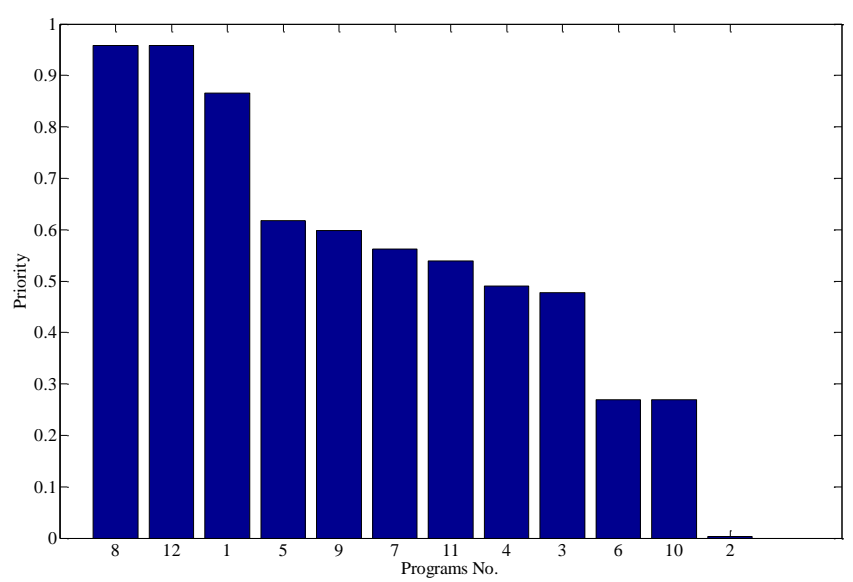

Fig. 4: The prioritization of different scenarios based on legislator's viewpoint

Figures 5 up to 7 show the office-building load of bus 9 in three different scenarios including after DR, after DR considering linear incentive and penalty and after DR considering nonlinear incentive and penalty. As can be seen from fig. 5, the results are similar in peak and off-peak periods, but the results of DR for power modeling is different in valley period. These results can be true for Fig. 6 and Fig. 7. The comparison between Fig. 5 and other figures, means Fig. 6 and Fig. 7, reveals the effect of incentive and penalty on DR. As can be clear, the reduction in linear model is considerable which means use of appropriate DR model is essential.

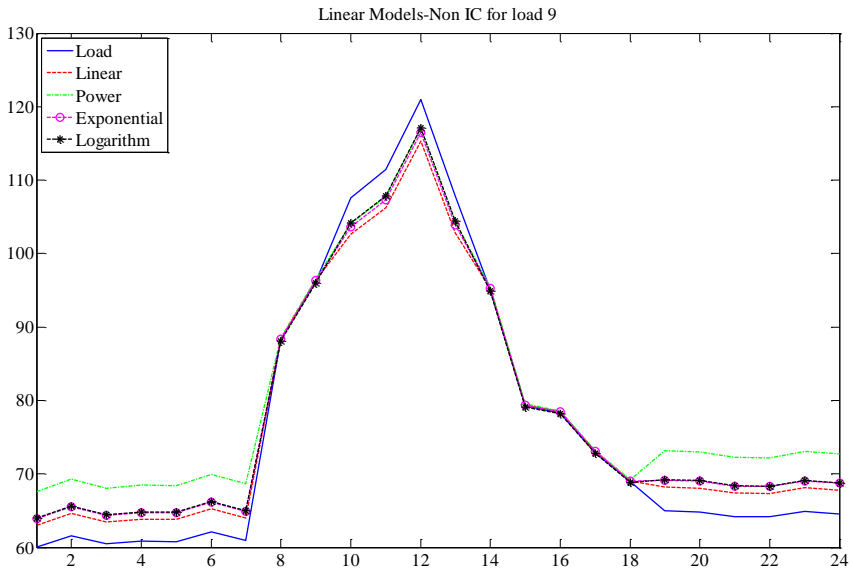

Fig. 5: Office-building Load of bus 9 in base and after DR

Figures 8 up to 10 show the commercial load of bus 12 in three different scenarios including after DR, after DR considering linear incentive and penalty and after DR considering nonlinear incentive and penalty. In this load; means commercial load; the results are match again with previous load; office-building load. With the presence of linear/nonlinear incentive and penalty, the linear model makes more reduction.

Figures 11 up to 13 show the residual load of bus 16 in three different scenarios including after DR, after DR considering linear incentive and penalty and after DR considering nonlinear incentive and penalty. The results show that the use of appropriate DR model is essential.

Based on the section 4, prioritization of scenarios are obtained as follow:

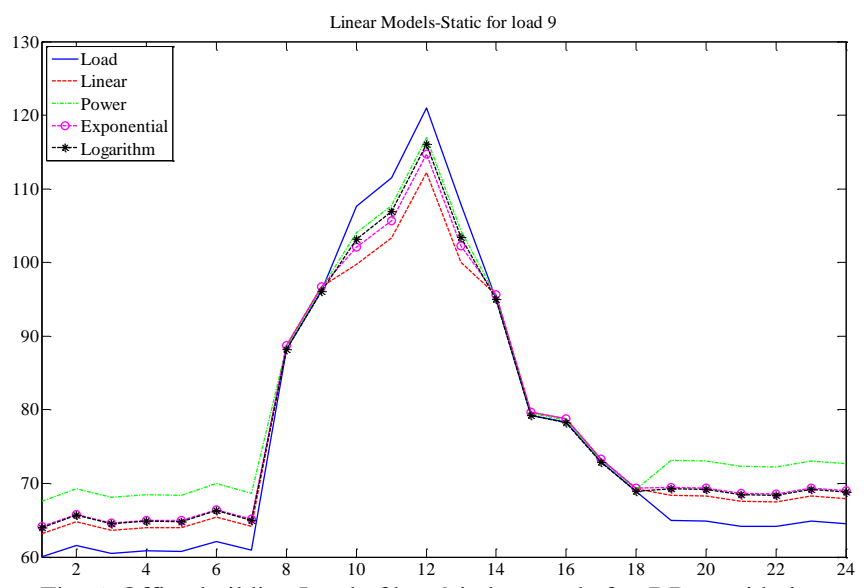

Fig. 6: Office-building Load of bus 9 in base and after DR considering linear incentive and penalty

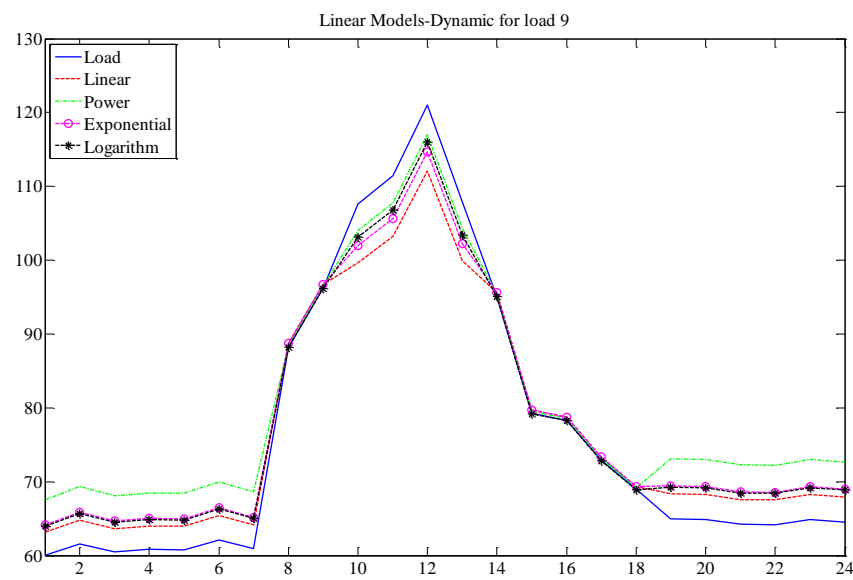

Fig. 7: Office-building Load of bus 9 in base and after DR considering nonlinear incentive and penalty

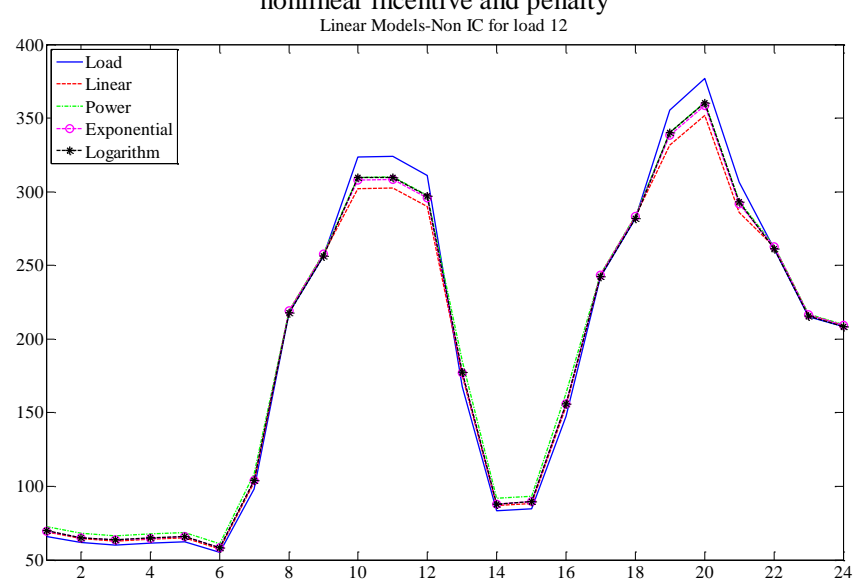

Fig. 8: Commercial Load of bus 12 in base and after DR

- $\quad$ Bus 9: DR considering linear incentive and penalty;

- Bus 12: DR considering linear incentive and penalty;

- Bus 16: DR considering nonlinear incentive and penalty;

- Bus 18: DR considering nonlinear incentive and penalty; 


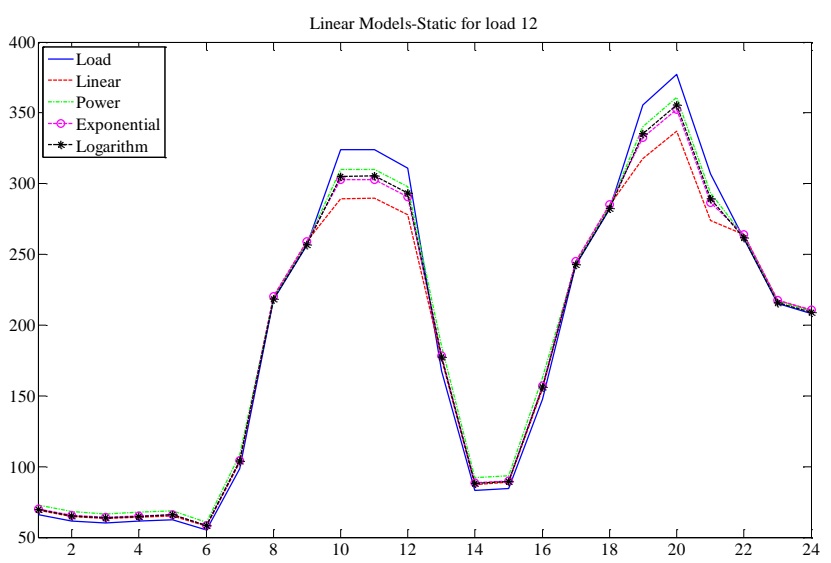

Fig. 9: Commercial Load of bus 12 in base and after DR considering linear incentive and penalty

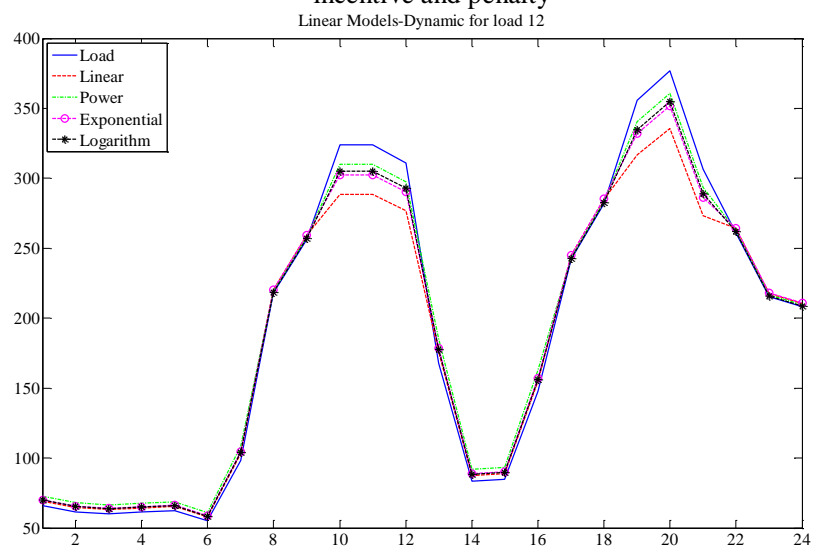

Fig. 10: Commercial Load of bus 12 in base and after DR considering nonlinear incentive and penalty

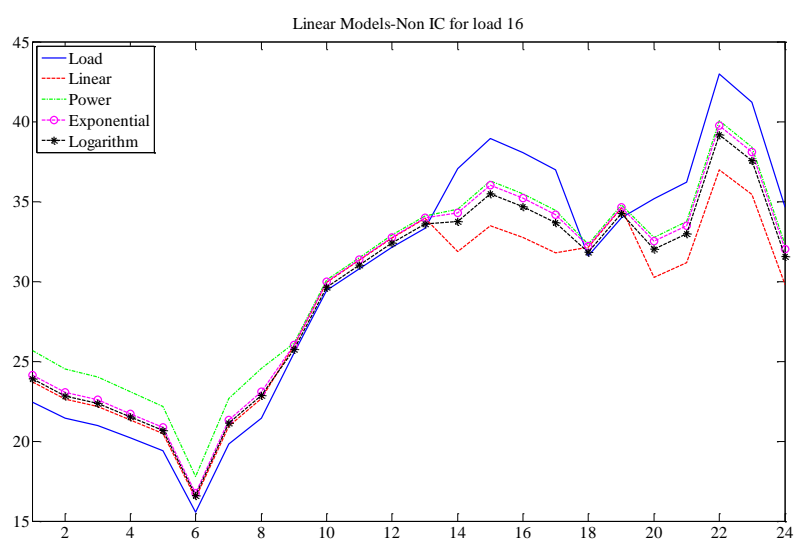

Fig. 11: Residual Load of bus 16 in base and after DR

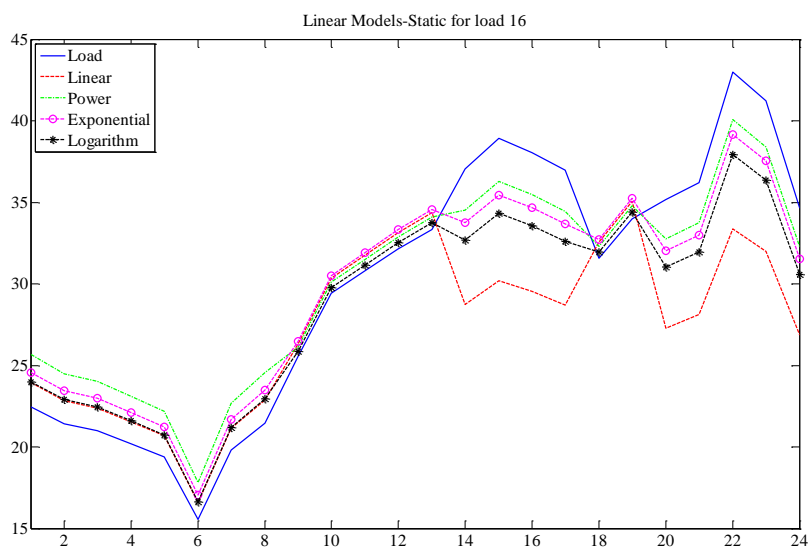

Fig. 12: Residual Load of bus 16 in base and after DR considering linear incentive and penalty

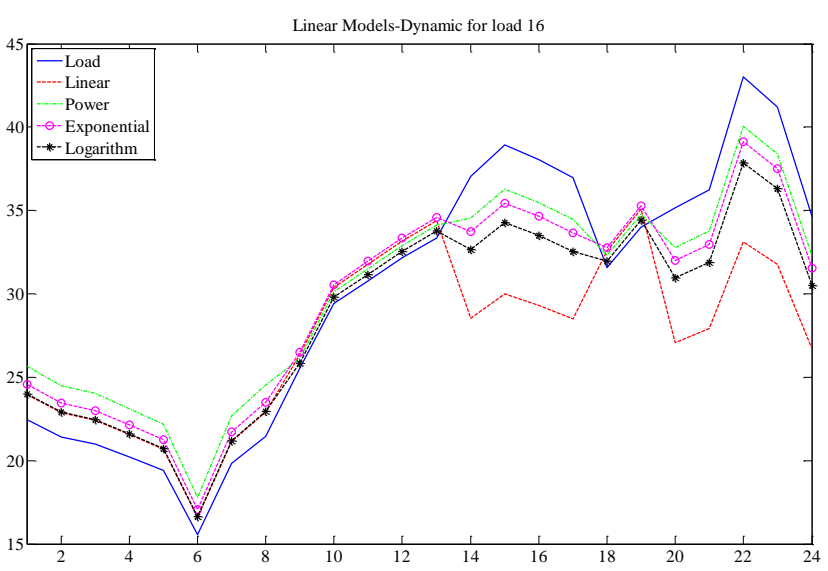

Fig. 13: Residual Load of bus 16 in base and after DR considering nonlinear incentive and penalty

It is worth to mention that for sample load, the NLDR based on Logarithmic modelling considering linear incentive and penalty leads to the best solution while for above loads, DR considering linear/nonlinear incentive and penalty leads to the best solution. This means that choosing the best solution depends on the load pattern. In other words, a method must be selected to consider all participant' viewpoint in the market and have a realistic behaviour, and this should be considered in the planning.

As the final aim of this paper is using DR results in TEP problems, in the following the TEP problem is solved by considering the realistic participation of buses 9, 12, 16 and 18 by the hierarchical method. Then the results are compared with logarithmic DR obtained in [29]. To do this and as the TEP problem must be performed in maximum load (worst case), the peak demand time should be specified. For this, the load of buses 9, 12, 16 and 18 are combined and the peak demand time is determined. The peak demand time is found as 20:00 and TEP problem solved. In Table V, output results of TEP problem and its comparison with [29] are provided.

TABLE V: OUTPUT RESULTS OF TEP PROBLEM AND ITS COMPARISON WITH [29]

\begin{tabular}{|c|c|c|c|c|c|}
\hline Item & $\begin{array}{l}\text { Loss } \\
\text { (MW) }\end{array}$ & $\begin{array}{l}\text { Cost of } \\
\text { Loss }(\$ / h)\end{array}$ & $\begin{array}{l}\text { Cost of } \\
\text { Generation } \\
(\$ / h)\end{array}$ & $\begin{array}{l}\text { Cost of Line } \\
\text { Construction } \\
(\$ / h)\end{array}$ & $\begin{array}{l}\text { Total } \\
\text { Cost } \\
(\$ / h) \\
\end{array}$ \\
\hline $\begin{array}{l}\text { The } \\
\text { results of } \\
\text { [29] }\end{array}$ & 9.8771 & 34.3722 & 37854 & 515.6575 & 38404 \\
\hline $\begin{array}{l}\text { The } \\
\text { obtained } \\
\text { results }\end{array}$ & 9.7228 & 33.8353 & 36462 & 515.5045 & 37011 \\
\hline
\end{tabular}

When appropriate DR is applied, the electrical network peak reduces which makes reduction of stresses on electrical equipment. Also, the lines congestion are removed and the subsequently lines capacity are released and fewer lines are needed. This decreases the different costs and ultimately reduces the total cost significantly. As can be seen from the Table V, the loss is decreased 0.1543 MW. The other items, including cost of loss, cost of generation, and cost of line construction are decreased $0.5365,1383$ and $0.153 \$ / \mathrm{h}$ which makes reduction of total cost equal to 1393 \$/h.

\section{CONCLUSION}

In this paper, the linear model of DR is studied simultaneously with nonlinear models including power, 
exponential and logarithmic of DR. Moreover, the effect of linear/nonlinear incentive and penalty is investigated. The results show that the use of appropriate DR model is essential. The study is investigated based on the viewpoint of different participants of the market including Independent System Operator (ISO), Customers and Utilities. The results show that choosing the best solution depends on the load pattern. In other words, a method must be selected to consider all participant' viewpoint in the market and have a realistic behaviour, and this should be considered in the planning.

\section{REFERENCES}

[1] A. S. Zakeri, H. Askarian Abyaneh, "Transmission Expansion Planning Using TLBO Algorithm in the Presence of Demand Response Resources”, Energies10.9 (2017): 1376.

[2] O. A. Gashteroodkhani, B. Vahidi, and A. Zaboli, "Time-time matrix z-score vector-based fault analysis method for series-compensated transmission lines," Turkish Journal of Electrical Engineering \& Computer Sciences, vol. 25, pp. 2647-2659, 2017.

[3] I. Niazazari, B. Vahidi, \& H. A. Abyaneh, "Loss reduction of wind turbine with optimization of blade length using genetic algorithm." Science International, 25(4), pp. $807-811,2013$

[4] L. L. Garver, "Transmission network estimation using linear programming", IEEE Transactions on Power Apparatus and Systems 7 (1970): 1688-1697.

[5] G. Latorre-Bayona, I. J. Perez-Arriaga, "Chopin, a heuristic model for long term transmission expansion planning", IEEE Transactions on Power systems9.4 (1994): 1886-1894.

[6] M. V. Pereira, L. M. Pinto, "Application of sensitivity analysis of load supplying capability to interactive transmission expansion planning", IEEE Transactions on Power Apparatus and Systems 2 (1985): 381389.

[7] A. Monticelli, A. Santos, M. V. F. Pereira, S. H. Cunha, B.J. Parker, J. C. G. Praca, "Interactive transmission network planning using a least-effort criterion", IEEE Transactions on Power Apparatus and Systems 10 (1982): 3919-3925.

[8] E. J. De Oliveira, I. C. da Silva, J. L. R. Pereira, S. Carneiro, "Transmission system expansion planning using a sigmoid function to handle integer investment variables", IEEE Transactions on Power Systems20.3 (2005): 1616-1621.

[9] V. Sarfi, I. Niazazari, and H. Livani, "Multiobjective fireworks optimization framework for economic emission dispatch in microgrids." North American Power Symposium (NAPS), 2016, pp. 1-6, Nov. 2016.

[10] V. A. Levi, M. S. Ćalović, "Linear-programming-based decomposition method for optimal planning of transmission network investments", IEE Proceedings C (Generation, Transmission and Distribution). Vol. 140. No. 6. IET Digital Library, 1993.

[11] I. Niazazari, H.A. Abyaneh, M. J. Farah, F. Safaei, andH. Nafisi,"Voltage profile and power factor improvement in PHEV charging station using a probabilistic model and flywheel," In Electrical Power Distribution Networks (EPDC), 2014 19th Conference on pp. 100-105. May. 2014

[12] M. V. F. Pereira, L. M. V. G. Pinto, S. H. F. Cunha, G. C. Oliveira, "A decomposition approach to automated generation/transmission expansion planning", IEEE Transactions on Power Apparatus and Systems 11 (1985): 3074-3083.

[13] O. A. Gashteroodkhani and B. Vahidi, "Application of Imperialistic Competitive Algorithm to Fault Section Estimation Problem in Power Systems," in The International Conference in New Research of Electrical Engineering and Computer Science, Iran, Sep 2015.

[14] R. A. Gallego, A. B. Alves, A. Monticelli, R. Romero, "Parallel simulated annealing applied to long term transmission network expansion planning", IEEE Transactions on Power Systems 12.1 (1997): 181-188.

[15] S. Binato, G. C. De Oliveira, J. L. De Araújo, “A greedy randomized adaptive search procedure for transmission expansion planning", IEEE Transactions on Power Systems 16.2 (2001): 247-253.
[16] O. A. Gashteroodkhani, M. Majidi, M. Etezadi-Amoli, A. F. Nematollahi, "A hybrid SVM-TT transform-based method for fault location in hybrid transmission lines with underground cables" Electric Power Systems Research, vol. 170, pp. 205-214, 2019.

[17] S. Aznavi, P. Fajri and A. Asrari, "Smart Home Energy Management Considering Real-Time Energy Pricing of Plug-in Electric Vehicles," in 2018 IEEE Energy Conversion Congress and Exposition (ECCE), Portland, OR, USA, 2018, pp. 67-72.

[18] S. Aznavi, P. Fajri, M. Benidris and B. Falahati, "Hierarchical droop controlled frequency optimization and energy management of a gridconnected microgrid," in 2017 IEEE Conference on Technologies for Sustainability (SusTech), Phoenix, AZ, USA, 2017, pp. 1-7.

[19] A. Vahid, Sh. Jadid, M. Ehsan, "Optimal Planning of a Multi-Carrier Microgrid (MCMG) Considering Demand-Side Management", International Journal of Renewable Energy Research (IJRER) 8.1 (2018): 238-249.

[20] Ö. Özdemir, F. D. Munoz, J. L. Ho, B. F. Hobbs, "Economic analysis of transmission expansion planning with price-responsive demand and quadratic losses by successive LP", IEEE Transactions on Power Systems 31.2 (2016): 1096-1107.

[21] K. S. Stille, J. Böcker, "Local demand response and load planning system for intelligent domestic appliances", Renewable Energy Research and Applications (ICRERA), 2015.

[22] I. Konstantelos, G. Strbac, "Valuation of flexible transmission investment options under uncertainty", IEEE Transactions on Power systems 30.2 (2015): 1047-1055

[23] Albadi, Mohamed H., and Ehab F. El-Saadany. "A summary of demand response in electricity markets." Electric power systems research 78.11 (2008): 1989-1996.

[24] Cappers P, Goldman C, Kathan D. Demand response in U.S electricity markets: empirical evidence. Energy April 2010;35(4). Demand response resources: the US and International Experience.

[25] Charles River Associates. Primer on demand-side management with an Emphasis on price-Responsive programs, Report prepared for The World Bank. Washington, DC, CRA No. D06090, 2005. Available online: <http://www.worldbank.org>, [accessed 11.10].

[26] M. Mirmozaffari, "Eco-Efficiency Evaluation in Two-Stage Network Structure: Case Study: Cement Companies," Iranian Journal of Optimization. vol.11, Issue 2, 2018.

[27] M. Mirmozaffari, A. Alinezhad, "Ranking of Heart Hospitals Using Cross-efficiency and Two-stage DEA," 7th International Conference on Computer and Knowledge Engineering (ICCKE) 26-27, Ferdowsi University of Mashhad, 978-1-5386-0804-31/17\$31.00@2 IEEE, October 2017.

[28] H. A. Aalami, M. Parsa Moghaddam, and G. R. Yousefi. "Evaluation of nonlinear models for time-based rates demand response programs." International Journal of Electrical Power \& Energy Systems 65 (2015): 282-290.

[29] A. S. Zakeri, H. Askarian-Abyaneh. "Investigation of Wind Power Uncertainty on Transmission Network Expansion Planning." International Journal of Renewable Energy Research (IJRER) 8.4 (2018): 1903-1912.

[30] K. Nigim, N. Munier, J. Green, Prefeasibility MCDM tools to aid communities in prioritizing local viable renewable energy sources, Elsevier, Renewable energy 29 (September (11)) (2004) 1775-1791.

[31] D. Cirio, G. Demartini, S. Massucco, A. Monni, P. Scaler, F. Silvestvo, G. Vimercati, Load control for improving system security and economics, in: IEEE, Power Tech Conference, vol. 4, June 2003 2003.

[32] M. Parsa moghaddam, M.K. Sheik-El-Eslami, S. Jadid, A MADM framework for generation expansion planning in small electricity firms, IEEE, Transaction on Power System (2005).

[33] H. A. Aalami, M. P. Moghaddam, and G. R. Yousefi. "Modeling and prioritizing demand response programs in power markets." Electric Power Systems Research 80.4 (2010): 426-435. 